\title{
Congestive Heart Failure Clinical Outcomes Study in a Private Community Medical Group
}

\author{
Louis A. Civitarese, DO, and Nicholas DeGregorio, $M D$
}

Background: Although angiotensin-converting enzyme (ACE) inhibitor therapy has been shown to improve clinical outcomes of patients with systolic dysfunction, it has been underused or prescribed in inadequate dosages by physicians in the treatment of congestive heart failure. Our goal was to evaluate whether integration of a clinical guideline within a continuous quality improvement program would improve care for patients with congestive heart failure caused by systolic dysfunction.

Metbods: All patients of a private community medical group who were admitted to the hospital with congestive heart failure were studied prospectively for 21 months. An internally developed congestive heart failure practice guideline was presented to the group's physicians. The guidelines were available in the hospital computer system and were reinforced at monthly quality improvement meetings. Performance data were reviewed quarterly with the physicians.

Results: Rates of classifying systolic vs diastolic dysfunction remained unchanged during the study. Use of ACE inhibitor therapy at the time of discharge improved substantially for patients with systolic dysfunction. Quarterly admissions of patients with systolic dysfunction declined $49 \%$ throughout the study period. No improvement was noted in the documentation of specific discharge instructions.

Conclusions: Use of a disease management guideline, ongoing physician education, and feedback of peer performance data to physicians significantly improved the quality and efficiency of care provided to patients with congestive heart failure in an independent, primary care medical group. (J Am Board Fam Pract 1999;12:467-72.)

In the book Making Integrated Health Care Work ${ }^{1}$ the authors stated, "We are not aware of any situations in which physicians in solo or small, singlespecialty groups have been involved in meaningful efforts to develop and implement clinical guidelines." The care that physicians provide for their patients, however, is now being measured more intensely than ever before, and techniques to improve the quality and efficiency of patient care are becoming valuable tools for today's physicians. As a result, continuous quality improvement processes are being incorporated into the private practice of medicine. The incorporation of an effective clinical guideline within the continuous quality improvement process can reduce unnecessary variation in clinical practice and can ultimately lead to im-

Submitted, revised, 22 January 1999.

From Preferred Primary Care Physicians, Pittsburgh. Address reprint requests to Louis A. Civitarese, DO, Preferred Primary Care Physicians, Scott Towne Center, 2101 Greentree Road, Suite B101, Pittsburgh, PA 15220.

Both authors are shareholder physicians with Preferred Primary Care Physicians. proved patient care. ${ }^{2,3}$ This report is an account of a clinical outcomes project undertaken by an independent 20-physician primary care medical group.

\section{Congestive Heart Failure: A High-Impact Diagnosis}

In the United States the clinical syndrome of congestive heart failure affects $1 \%$ of the general population and $10 \%$ of the population older than 65 years. ${ }^{4}$ In the group of patients older than 65 years, congestive heart failure was the most common admitting diagnosis. The medical literature has established improved symptom control, exercise tolerance, and survival for patients whose congestive heart failure and systolic dysfunction (left ventricular ejection fraction of 0.40 or less) are treated with angiotensin-converting enzyme (ACE) inhibitor therapy. ${ }^{5-7}$ The SOLVD (Study of Left Ventricular Dysfunction) trial showed a reduction in hospitalizations from $36.6 \%$ to $25.8 \%$ for patients with mild to moderate congestive heart failure who were receiving ACE inhibitor therapy. ${ }^{5,8}$ 
In general, there has been considerable variation in the treatment of diseases by physicians." Specifically, such variation has affected the care of patients with congestive heart failure. ${ }^{5}$ Too often the distinction between systolic and diastolic dysfunction has not been determined in clinical practice, and studies have confirmed that ACE inhibitor therapy has been underutilized in treating systolic dysfunction. ${ }^{10}$ Because congestive heart failure is common and effective treatment is available, yet underprescribed, we found congestive heart failure to be an excellent diagnosis for an outcomes study.

\section{Methods}

Study Goal

The goal of this study was to evaluate whether implementing a congestive heart failure clinical guideline within the continuous quality improvement process would lead to more frequent and optimal use of ACE inhibitors in the treatment of systolic congestive heart failure and therefore decrease the number of hospital admissions for this diagnosis.

\section{Characteristics of the Medical Group}

Preferred Primary Care Physicians, located in Pittsburgh, is an independent, 20-physician primary care medical group made up of 10 family physicians and 10 internists, of whom 13 are shareholders. The group has a 7-physician board of directors, a centralized business office, an executive director, a medical director, a 4-physician quality improvement committee, and 2 full-time employees ( 1 registered nurse and 1 clinical assistant) dedicated to clinical projects and outcomes measurement.

\section{Study Design and Practice Guideline}

This prospective study, conducted for a period of 21 months from 1 November 1995 to 31 July 1997, included all patients admitted to the group's primary community-based hospital. Patients were selected for inclusion in the study if on a medical record review they had a confirmed discharge diagnosis of congestive heart failure (International Classification of Diseases, code 428). ${ }^{11}$ The attending physician determined the primary discharge diagnosis, defined as the single disease process most responsible for the patient's admission. Hospital- based case management nurses performed basel and quarterly medical record reviews.

The designated physicians in the group developed a guideline for congestive heart failure based on a literature review and several preexisting guidelines from hospital systems and health plans. T趈e guideline was presented to the group at a forri⿱宀 continuing medical education session at the outsot of the study. Discussion of the most recent liteture in the treatment of congestive heart failife took place to affirm the scientific credibility of guideline. All physicians were given ample time $\tilde{c}_{\text {to }}$ comment on the guideline and study design. Affer appropriate modifications, approved by group catsensus, each physician verbally endorsed the plifir.

The final product was a comprehensive, dise state management program applicable to both he inpatient and outpatient settings. This guideline was addressed at the group's monthly quality i provement meetings, was available to the physicians for reference in the hospital computer system located at all clinical sites within the facility, a a was in a ring binder in every physician office wittin the group. Although the guideline was comprehensive, the following three primary objectives we $\vec{e} \mathrm{e}$ emphasized at each monthly quality improvemênt meeting:

1. All patients with congestive heart failure requक्षि an assessment of left ventricular function to termine appropriate treatment.

2. Patients found to have systolic congestive he failure should have an ACE inhibitor medication prescribed that is titrated to a targeted optin dosage, as tolerated, provided there are no coiptraindications.

3. All patients with congestive heart failure shou be instructed to weigh themselves daily on the same scale and to telephone their physicians office if they experience a predetermined amoug of short-term weight gain.

Standardized inpatient admission orders wexe developed to parallel the congestive heart failuse guideline and prompt the physicians to address every decision point. The physicians were apprised of their performance data at the quarterly qualioy improvement meetings. The group decided at the outset to share the individual and aggregate cli⿺辶่cians' data openly with all physicians in the grous. 
Table 1. Data from Medical Record Review of Patients Admitted to the Hospital with Congestive Heart Failure.

\begin{tabular}{|c|c|c|c|c|c|}
\hline $\begin{array}{l}\text { Patient and Treatment } \\
\text { Characteristics }\end{array}$ & $\begin{array}{l}\text { 1 Nov 1995- } \\
\text { 31 Jan } 1996 \\
\text { No. (\%) }\end{array}$ & $\begin{array}{l}\text { 1 Feb } 1996- \\
30 \text { Apr } 1996 \\
\text { No. }(\%)\end{array}$ & $\begin{array}{c}1 \text { May } 1996- \\
31 \text { Jul } 1996 \\
\text { No. (\%) }\end{array}$ & $\begin{array}{c}1 \text { Aug } 1996- \\
31 \text { Oct } 1996 \\
\text { No. }(\%)\end{array}$ & $\begin{array}{c}1 \text { May } 1997- \\
31 \text { Jul } 1997 \\
\text { No. (\%) }\end{array}$ \\
\hline Total number of patients & 66 & 59 & 52 & 51 & 47 \\
\hline Diastolic dysfunction & $25(38)$ & $22(37)$ & $29(56)$ & $27(53)$ & $26(55)$ \\
\hline Systolic dysfunction & $35(53)$ & $32(54)$ & $20(38)$ & $19(37)$ & $17(36)$ \\
\hline Not determined & $6(9)$ & $5(9)$ & $3(6)$ & $5(10)$ & $4(9)$ \\
\hline $\begin{array}{l}\text { Patients readmitted with recurrent } \\
\text { congestive heart failure } \\
\text { within } 30 \text { days }\end{array}$ & $5(8)$ & $3(5)$ & $2(4)$ & $1(2)$ & $2(4)$ \\
\hline Patients with systolic dysfunction & 35 & 32 & 19 & 19 & 15 \\
\hline On ACE inhibitor at admission & $17(49)$ & $18(56)$ & $13(69)$ & $10(53)$ & $8(53)$ \\
\hline Same dosage at discharge & $7(41)$ & $7(39)$ & $4(30)$ & $5(50)$ & $5(63)$ \\
\hline Dosage changed at discharge & $7(41)$ & $9(50)$ & $6(46)$ & $4(40)$ & $2(25)$ \\
\hline Other & & $\begin{array}{l}1 \text { patient } \\
\text { transferred }\end{array}$ & $\begin{array}{l}2 \text { patients CTB; } \\
1 \text { patient ACE } \\
\text { inhibitor initial } \\
\text { dosage unrecorded }\end{array}$ & $\begin{array}{l}1 \text { patient CTB, } \\
1 \text { patient } \\
\text { transferred }\end{array}$ & $\begin{array}{l}1 \text { patient CTB; } \\
1 \text { patient } \\
\text { transferred }\end{array}$ \\
\hline Not on ACE inhibitor at admission & $18(51)$ & $14(44)$ & $5(26)$ & $9(47)$ & $7(47)$ \\
\hline Discharged on ACE inhibitors & $12(67)$ & $4(29)$ & $4(80)$ & $2(22)$ & $6(86)$ \\
\hline No ACE inhibitor at discharge & $6(33)$ & $9(64)^{*}$ & $1(20)^{*}$ & $5(56)$ & $1(14)^{*}$ \\
\hline Other & & 1 patient CTB & & & \\
\hline
\end{tabular}

ACE-angiotensin-converting enzyme.

C'TB-cease to breathe.

*Indicates quarters in which $100 \%$ of patients were discharged on ACE inhibitors or met exclusion criteria.

\section{Measurements}

The following data were obtained from baseline and quarterly inpatient medical record audits:

1. Left ventricular function measurement by echocardiogram or multigated angiogram within 1 year of admission or sooner if there had been an intercurrent cardiac event

2. ACE inhibitor treatment for congestive heart failure for patients with confirmed systolic dysfunction, defined as a left ventricular ejection fraction of 0.40 or less

3. Appropriate adjustment to achieve optimal ACE inhibitor therapy, as tolerated, according to the following target doses: (1) enalapril-10 $\mathrm{mg}$ twice a day, (2) captopril- $50 \mathrm{mg}$ three times a day, (3) lisinopril-20 mg every day, and (4) quinapril-20 $\mathrm{mg}$ twice a day. Maximal doses were considered in patients depending upon their clinical responses to ACE-inhibitor therapy

4. Documentation of one or more of the following contraindications to prescribing $\mathrm{ACE}$ inhibitors for congestive heart failure for patients with systolic dysfunction who were not treated with
ACE inhibitor: (1) history of intolerance to ACE inhibitors, (2) serum potassium $>5.5 \mathrm{mEq} / \mathrm{L}$, (3) serum creatinine $>3.0 \mathrm{mg} / \mathrm{dL}$, (4) systolic blood pressure $<90 \mathrm{~mm} \mathrm{Hg}$, (5) severe ACE inhibitor-related cough, (6) bilateral renal artery stenosis, or (7) pregnancy

5. Confirmation that patients received instructions by physicians to weigh themselves daily and telephone their physicians if they gained more than 2 pounds in 1 day or more than 3 pounds in 1 week

6. Documentation of dietary instructions

7. The number of patients admitted with congestive heart failure

8. The number of patients readmitted with congestive heart failure within 30 days of discharge

\section{Results}

\section{Significant Reduction in Systolic Dysfunction Admissions}

The data from the study audits are displayed in Table 1. Two hundred seventy-five patients were included in the study. During the study the total patient population increased, but the patient demographics remained unchanged. The percentage of 


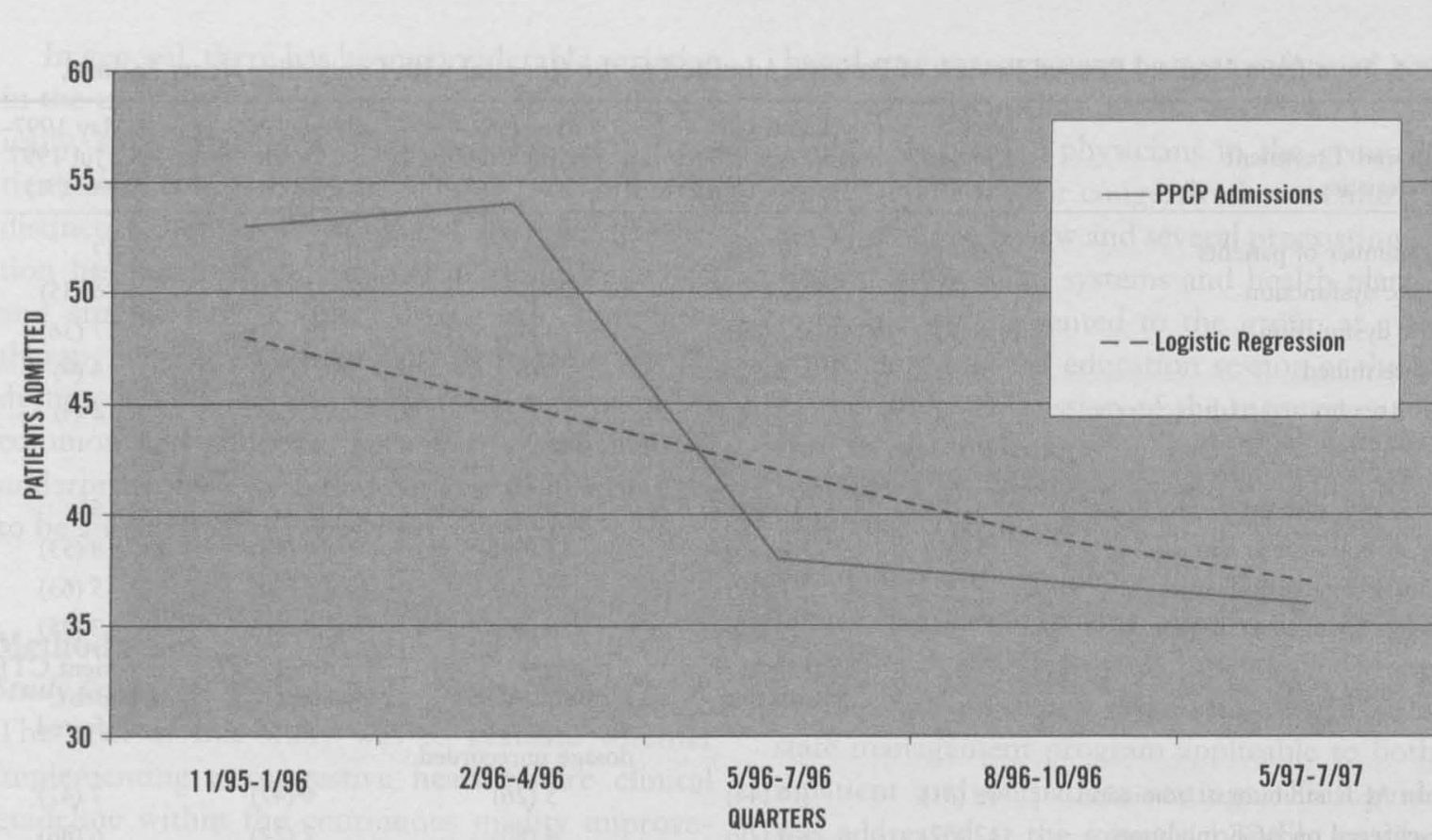

Figure 1. Percentage of patients admitted with congestive heart failure with systolic dysfunction, by quarter.

patients admitted to the hospital with documented left ventricular function did not change considerably during the study. Ninety-two percent of patients were characterized as having systolic or diastolic dysfunction, whereas this condition was not determined in approximately $8 \%$ of patients. The percentage of patients on ACE inhibitor therapy, as well as ACE inhibitor dosages upon admission, remained relatively constant throughout the study. By the end of the study, however, $100 \%$ of patients with confirmed systolic dysfunction were either discharged with prescriptions for ACE inhibitors or had documentation that they met exclusion criteria for ACE inhibitor therapy.

Using logistic regression analysis, we found that during the study there was a significant decrease in the percentage of systolic congestive heart failure admissions with time $(P=.0279$ (Figure 1). There was a $49 \%$ reduction in the absolute number of patients admitted for congestive heart failure caused by systolic dysfunction throughout the study $(P=.0367)$. The absolute number of patients admitted with diastolic dysfunction remained steady throughout the study. By the end of the study, however, diastolic dysfunction accounted for a substantially larger percentage of all congestive heart failure admissions. Documentation of diet and self-weighing instructions to patients was suboptimal.

\section{Evidence of Guideline Use in Outpatient and Inpatient Practice}

Although this study was hospital-based, the congestive heart failure guideline was emphasized gid made available to physicians in their offices as well as the hospital. We believe that an increase in ghe outpatient use of ACE inhibitor therapy for $c$ हn gestive heart failure was a major contributor to क्षे reduction in hospital admissions for that diagno This belief was strongly supported by outpatiönt pharmacy utilization data from Aetna US Hea照care, which showed a $39 \%$ increase in ACE in itor use by patients with congestive heart fails re who were cared for by physicians in our group during the course of this study. ${ }^{12}$

\section{Conclusions}

The results of this study show a statistically signifficant decrease in the number of admissions for congestive heart failure caused by systolic dysfufriction during a specified period subsequent to $\mathbb{W}_{\mathrm{W}}$ implementation of a clinical guideline for congstive heart failure. It is our belief that this decresse was a result of the more frequent and optirg్g్al inpatient and outpatient use of ACE inhibitor me्gi-

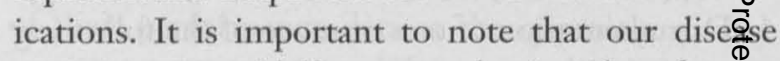
management guideline stressed principles of tre्त tment that were identical for both inpatients outpatients. 
Although we would have preferred to collect our own data to prove increased ACE inhibitor therapy for outpatient treatment of systolic dysfunction, we were able to obtain supporting pharmacy data from health care insurers. The rate of inpatient use of ACE inhibitor therapy and the rate of hospital admissions, however, could be tracked easily by means of a hospital-based utilization review. Hospital admission rate was used as a measurement of quality and as a major outcomes indicator in the landmark SOLVD trial. It is our belief, therefore, that a reduction in the number of hospital admissions for congestive heart failure, the $100 \%$ appropriate usage of ACE inhibitors in three of the last four quarters, and a greater than $90 \%$ rate of left ventricular ejection fraction determination throughout the study were sound indicators of improved quality of care in the treatment of congestive heart failure. We met our study goal, and we found that a disease management guideline, when properly developed and applied, could lead to improved outcomes in a community-based medical group.

We were concerned that $8 \%$ of patients admitted for congestive heart failure admissions had no determination of systolic or diastolic dysfunction. Follow-up investigation with physicians, however, showed that these patients frequently had limited code status, and additional testing was not desired or consistent with the goals of therapy. Many of these patients were admitted for placement purposes and for comfort care only.

Patient education pertaining to diet and selfweighing was poorly documented. Based on discussions with the physicians, it is probable that patients were instructed regarding diet and weight often without documentation. To address this problem, a congestive heart failure treatment worksheet was subsequently developed and implemented to document each aspect of patient education. The education process begins when the patient is admitted to the hospital, and each item is checked off and initialed when completed. At the end of the hospitalization, the patient receives a copy as $\bar{a}$ discharge instruction sheet. It is signed by the patient, who then becomes an active participant in his or her own care.

In the opinion of these investigators, the success of this project depended on the following key elements:

1. We selected a disease process that is commonly seen and treated by primary care physicians.
2. We developed ą meaningful and credible clinical practice guideline.

3. The clinical study design was relatively simple and straightforward, and focused on a few key outcomes.

4. The guideline and study design was endorsed by every physician involved in the study.

5. The practice guideline was reinforced (1) by its availability on the hospital computer system and in every physician's office, (2) by the use of standardized congestive heart failure admission orders that followed every key decision point in the guideline, and (3) by reminders at the group's monthly quality improvement meetings and in our monthly newsletter.

6. Quarterly updates of peer performance data were shared among all of the physicians.

7. We used a risk pool with compensation methods based, in part, on clinical outcome data specific to each physician.

8. The costs of both implementation and outcomes measurement were kept within the budget of our quality improvement committee.

Although sharing performance data among physicians was a sensitive issue, it was well received when done in a collaborative, educational manner. The group's experience and success with this study has resulted in enthusiasm for the development and implementation of similar projects for other disease states. In the future, progress will be facilitated by published guidelines that can be easily adapted for use within medical practices.

This study illustrates the value of implementing clinical guidelines as part of a complete continuous quality improvement program. Achieving highquality primary care within a medical group and actually measuring it can be an expensive undertaking. We accomplished our study at a relatively low cost to the physicians, and we therefore believe that it would be easy to undertake similar studies in other primary care medical groups. Such efforts are no longer novel, but essential, as physician accountability has evolved into an everyday reality. ${ }^{13,14}$ The community-based outcomes study can be used as a powerful tool to reduce the unnecessary variation that is the curse of clinical quality and efficiency. For physicians, favorable outcomes data will be requisite to contract for patients. For employers, they could result in lower costs, and most importantly, it will mean better care for patients. 
The physicians of Preferred Primary Care Physicians provided support in conception, design, and participation in the study. Highmark/Blue Cross Blue Shield and Jill Suhrie provided statistical support. St Clair Hospital, Case Management Department, Mt. Lebanon, Pa, and in particular Linda Best, RN, provided their support in data collection; and Doreen E. Bonicky, $\mathrm{RN}$, provided her invaluable assistance in preparing the tables and in adding clarity and focus to the manuscript.

\section{References}

1. Coddington DC, Fischer EA, Moore KD. Making integrated health care work. Englewood, Colo: Center for Research in Ambulatory Health Care Administration, 1996.

2. Grimshaw J, Freemantle N, Wallace S, et al. Developing and implementing clinical practice guidelines. Qual Health Care 1995;4:55-64.

3. Kibbe DC, Kaluzny AD, McLaughlin CP. Integrating guidelines with continuous quality improvement: doing the right thing the right way to achieve the right goals. Jt Comm J Qual Improv 1994;20:18191.

4. Fauci AS, Braunwald E, Isselbacher KJ, et al, editors. Harrison's principles of internal medicine, 14th ed. New York: McGraw-Hill, 1998.

5. Fonarow GC, Walden JA, Livingston $\mathrm{N}$, Hamilton MA, Moriguchi J, Stevenson LW. Effective management for patients with congestive heart failure. Cardiol Rev 1998;15:13-6.

6. Garg R, Yusuf S. Overview of randomized trials of angiotensin-converting enzyme inhibitors on mor- tality and morbidity in patients with heart failuree. Collaborative Group on ACE Inhibitor Trials. JAM 1995;273:1450-6.

7. Effect of enalapril on survival in patients with rete duced left ventricular ejection fractions and congentive heart failure. The SOLVD Investigators. $N$ Eng్ J Med 1991;325:293-302.

8. Effect of enalapril on mortality and the development of heart failure in asymptomatic patients with r $\overrightarrow{\bar{E}}$ duced left ventricular ejection fractions. The SOLVד Investigators. N Engl J Med 1992;327:685-91.

9. Cave DG, Geehr EC. Analyzing patterns-of-trea ment data to provide feedback to physicians. Me̊d Interface 1994july:117-26.

10. Ofili EO. Review of the current clinical practice guidelines-management of heart failure. ABC Digest Urban Cardiol 1994; Nov-Dec: 8-20.

11. ICD-9-CM, 1997: international classification of $d \overrightarrow{\mathbb{P}^{2}}$ eases. Vols 1 and 2. New York: McGraw-Hill, $199 \overrightarrow{8}$.

12. Aetna US Healthcare data. PCP cardiac perfợomance report. 5/1/96-4/30/97 \& 4/1/97-3/31/9 . Pittsburgh: Aetna US Healthcare, 1997. (Report flecting sampling of PCP patients evaluated for coggestive heart failure and appropriate ACE inhibiter therapy.)

13. O'Leary DS. The measurement mandate: Repợt card day is coming. Am J Hosp Pharm 1994;51:75 居 61.

14. Topol EJ, Califf RM. Scorecard cardiovascular me $\overrightarrow{8}$ icine. Its impact and future directions. Ann Intern Med 1994;120:65-70. 